\title{
Topography of thin films containing Ni-Ga intermetallic compounds formed on $\mathrm{GaN}(0001)$
}

\author{
Justyna Pers*, Miłosz Grodzicki and Antoni Ciszewski \\ Institute of Experimental Physics, University of Wrocław, pl. Maksa Borna 9, 50-204 \\ Wrocław, Poland
}

\begin{abstract}
Studies, carried out in situ by scanning tunneling microscope (STM), on the topography of thin films containing Ni-Ga intermetallic compounds are presented in this report. It is shown that conditions of the film preparation influence size and shape of 3-D formations constituted of the compounds. The films are formed in two ways. The first one in which pre-deposited at room temperature $\mathrm{Ni}$ film is annealed at $650{ }^{\circ} \mathrm{C}$, and the second one where $\mathrm{Ni}$ is evaporated directly onto the substrate kept at $650{ }^{\circ} \mathrm{C}$. Films obtained by using the second procedure should be more suitable for catalytic applications. Grains of the compounds formed in these films do not show tendency for coalescence and are more strongly dispersed in contrary to the grains formed in the films obtained by using first procedure.
\end{abstract}

Keywords: Ni-Ga intermetallic compounds, GaN(0001), Grains, STM

\section{Introduction}

The studies of catalytic systems of high efficiency conversion of carbon dioxide into liquid fuel have grown rapidly in the past few years. The interest is caused by increasing amount of carbon dioxide in the earth atmosphere and the global demand for fuel. Due to its good efficiency and selectivity Ni-Ga intermetallic compounds are important catalysts, which could be used for development of low-pressure small-scale devices for $\mathrm{CO}_{2}$ reduction to $\mathrm{CH}_{3} \mathrm{OH}[1,2]$. In order to increase catalytic efficiency of the compounds their highly dispersed form fixed on an unreactive support is required.

Herein we report the results of STM studies on the influence of deposition conditions on the topography of thin films containing Ni-Ga intermetallic compounds formed on $\mathrm{GaN}(0001)$ surface. Due to its chemical resistivity and high temperature resistance GaN should be

\footnotetext{
* Corresponding author: (J. Pers) jpers@ifd.uni.wroc.pl, tel. (+48 -71) 3759301
} 
considered as promising material which could support highly dispersed metallic catalysts. Particularly these of the bi-metallic catalysts which contains gallium. Under annealing above $500{ }^{\circ} \mathrm{C}$ the $\mathrm{GaN}$ surface enriches with Ga. It creates possibility to use this $\mathrm{Ga}$ in order to form bi-metallic catalyst by evaporating the second metal component straight onto the GaN surface. It is proved that annealing of thin $\mathrm{Ni}$ films deposited on $\mathrm{GaN}$ results in $\mathrm{Ni}-\mathrm{Ga}$ intermetallic compounds formation $[3,4]$. The compounds are formed on the surface as a result of gradual alloying of metallic Ni deposited in doses on the substrate surface and metallic Ga that develops on the surface during annealing. Nitrogen, the partial pressure of which is much higher than the gallium partial pressure, is released at temperature above $550{ }^{0} \mathrm{C}$ from the surface and subsurface regions of the substrate into vacuum leaving droplets of metallic Ga on the surface. Alloying of this Ga with Ni results in 3-D formations of nanometer dimensions containing $\mathrm{Ni}-\mathrm{Ga}$ intermetallic compounds mostly as $\mathrm{Ni}_{3} \mathrm{Ga}$ phase [4].

\section{Experimental details}

Samples, around $8 \times 4 \mathrm{~mm}^{2}$ in size, cut out from a $\mathrm{GaN} / \mathrm{Al}_{2} \mathrm{O}_{3}$ wafer (TDI Inc.) terminated with $10 \mu \mathrm{m}$ thick epitaxial GaN layers, (0001)-oriented, Si-doped $\left(N_{d}=10^{18} \mathrm{~cm}^{-3}\right)$ were used as substrates. The research was carried out in situ by scanning tunneling microscopy (STM) in an ultrahigh vacuum (UHV) chamber with the base pressure $\sim 1 \times 10^{-10}$ Torr.

Before the formation of $\mathrm{Ni}-\mathrm{Ga}$ thin films on $\mathrm{GaN}(0001)$, the substrates were ex situ degreased in isopropanol, subsequently they were washed in distilled water and dried in air, next mounted on molybdenum plates and disposed in UHV. The substrate surface was cleaned in situ by cycles of annealing at $800{ }^{\circ} \mathrm{C}$ in order to remove surface oxides and carbon contamination. Heating of samples was done by electron bombardment (from the backside of the substrate). The temperature was monitored by a pyrometer. The thin films containing NiGa intermetallic compounds were formed on $\mathrm{GaN}(0001)$ in two different ways. The first, in which $\mathrm{Ni}$, pre-deposited under UHV on the substrate kept at room temperature (RT), was afterwards annealed at $650{ }^{\circ} \mathrm{C}$ (a post-deposition annealing). The second way of engineering the films was directly deposited of $\mathrm{Ni}$ on $\mathrm{GaN}(0001)$ surface kept at $650{ }^{\circ} \mathrm{C}$. The $\mathrm{Ni}$ with 99.99\% purity from Sigma-Aldrich was used as adsorbate and was evaporated from an electron beam evaporator under an operating pressure lower than $5 \times 10^{-10}$ Torr. STM topographies were recorded in constant current mode with bias voltages from 3.5 to $5 \mathrm{~V}$ at tunneling currents ranging from 0.2 to $1.0 \mathrm{nA}$. Electrochemically etched tungsten wires were 
used as tips. The obtained images were analyzed using the WSxM and Gwyddion software [5,6]. All the measurements were done at RT.

\section{Results and Discussion}

A typical morphology of the Ni-Ga film formed by the post-deposition annealing at $650{ }^{0} \mathrm{C}$ is shown in Fig. 1a. As reported previously, the annealing of the Ni films deposited on $\mathrm{GaN}(0001)$ results in Ni-Ga surface alloying and the dominating phase formed is $\mathrm{Ni}_{3} \mathrm{Ga}$ [4]. Formation of the 3D islands rich with the $\mathrm{Ni}-\mathrm{Ga}$ compounds is accompanied by their coalescence. Coalescing islands of average width ranging from 10 to $20 \mathrm{~nm}$ and height of about $2 \mathrm{~nm}$ create meandering chains (see Fig. 1b). Surface area occupied by a single chain ranges from $100 \mathrm{~nm}^{2}$ to $3250 \mathrm{~nm}^{2}$. Statistical analysis show that average surface area of a single chain amounted to about $900 \mathrm{~nm}^{2}$, and that most of the chains had the surface area of about $250 \mathrm{~nm}^{2}$.
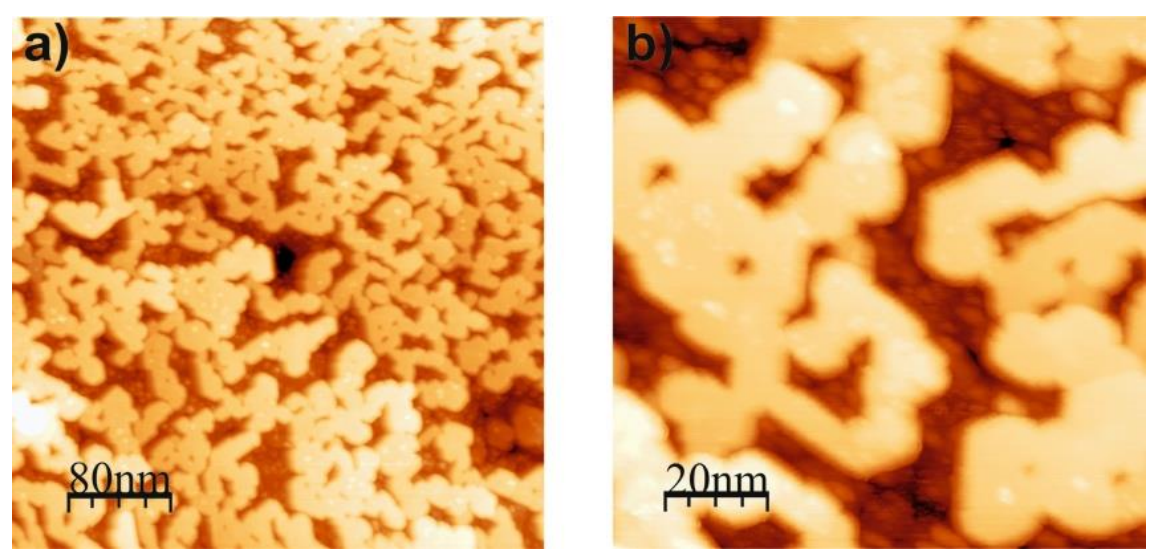

Figure 1. STM topography of the Ni film deposited at RT on GaN(0001) and post-deposition annealed at $650{ }^{\circ} \mathrm{C}$. The film is about $3 \mathrm{~nm}$ thick in average. Imaging area equals (a) $400 \times$ $400 \mathrm{~nm}^{2}$, and (b) $100 \times 100 \mathrm{~nm}^{2}$. Range of the color scale amounts (a) from 0 to $6 \mathrm{~nm}$ and (b) from 0 to $4 \mathrm{~nm}$.

Direct deposition of $\mathrm{Ni}$ on clean $\mathrm{GaN}(0001)$ surface kept at $650{ }^{\circ} \mathrm{C}$ results in grainy morphology of the growing films. The grains of polygonal (mostly of irregular hexagon) shape are uniformly distributed over the surface as is visible in Fig. 2a and b. 

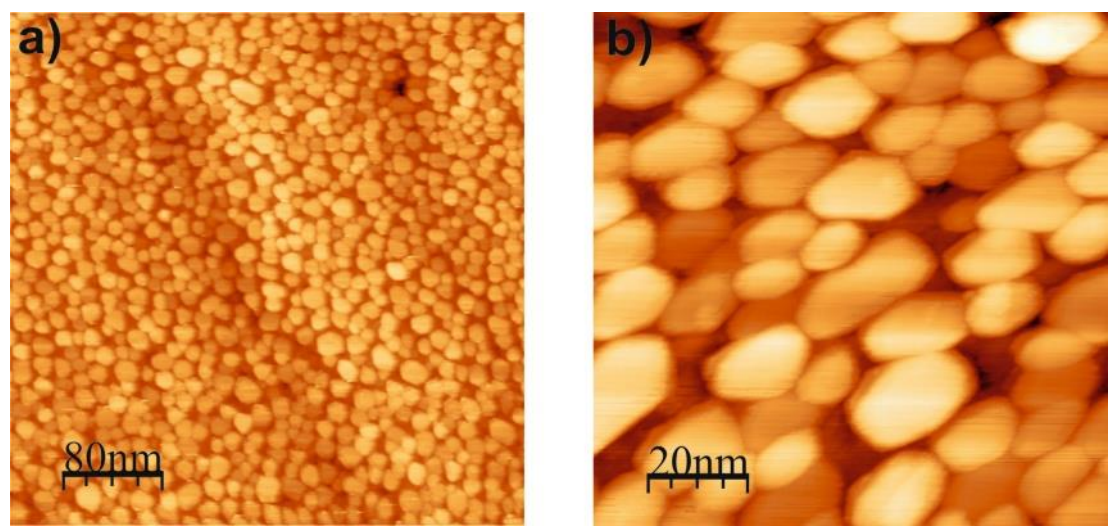

Figure 2. STM topography of Ni layers of mean thickness equal to about $1.5 \mathrm{~nm}$ deposited on GaN(0001) surface kept at $650{ }^{\circ} \mathrm{C}$. Imaging area equals to (a) $400 \times 400 \mathrm{~nm}^{2}$, and (b) $100 \times$ $100 \mathrm{~nm}^{2}$. Range of the color scale amounts from 0 to $3 \mathrm{~nm}$. Film topography is substantially different than that in Fig. 1. The grains are mostly of the shape of irregular hexagon.

Analysis of the size distribution of the surface area occupied by a single grain shows that: it ranges from $50 \mathrm{~nm}^{2}$ to $400 \mathrm{~nm}^{2}$; mean surface area of a grain amounts to $140 \mathrm{~nm}^{2}$; most of the grains have surface area of about $150 \mathrm{~nm}^{2}$. Further deposition decreases dispersing of the deposit. The topography of the film becomes more uniform. An example is shown in Fig 3. Average thickness of the film shown in Fig. 3 is equal to about $3 \mathrm{~nm}$ (it corresponds to average thickness of the film shown in Fig 1). Dispersing of the deposit in this case is still stronger than in the case of the film of the same thickness deposited using the first postdeposition annealing method (compare with Fig. 1). Surface area occupied by a single grain ranges from $50 \mathrm{~nm}^{2}$ to $850 \mathrm{~nm}^{2}$, the mean area of a single grain amounts to $350 \mathrm{~nm}^{2}$.
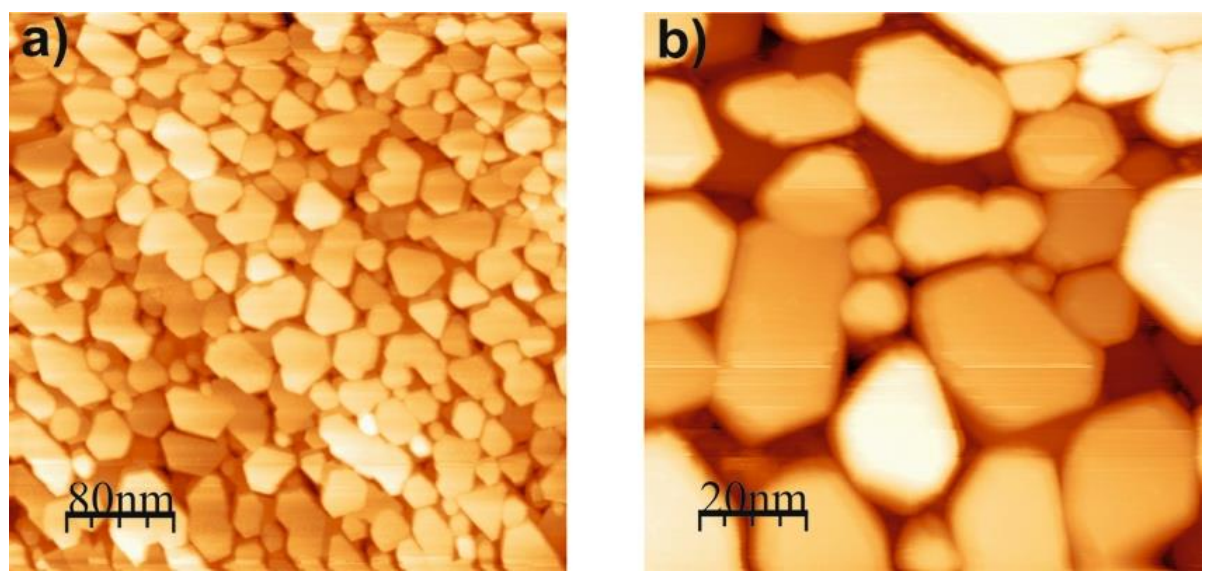

Figure 3. STM images after further deposition of $\mathrm{Ni}$ on $\mathrm{GaN}(0001)$ surface kept at $650{ }^{\circ} \mathrm{C}$. The whole deposited Ni layer is about $3 \mathrm{~nm}$ thick in average. Imaging area equals to (a) 400 $\times 400 \mathrm{~nm}^{2}$, and (b) $100 \times 100 \mathrm{~nm}^{2}$. The range of the color scale amounts from 0 to $3 \mathrm{~nm}$. The grains are visibly separated. 


\section{Conclusions}

It has been demonstrated that conditions of deposition influence topography of thin films containing Ni-Ga intermetallic compounds formed on $\mathrm{GaN}(0001)$ surface. The compounds develop in the form of 3-D grains independently on the way of formation. Films formed on $\mathrm{GaN}(0001)$ surface kept at $650{ }^{\circ} \mathrm{C}$ exhibit a higher degree of dispersing of the grains than films deposited on the surface kept at RT and next annealed. Grains of the compounds formed by direct deposition of $\mathrm{Ni}$ on the substrate kept at $650{ }^{\circ} \mathrm{C}$ also show no tendency for coalescence therefore these films should be more suitable for catalytic applications.

\section{Acknowledgments}

The work was supported by the Wroclaw Research Centre EIT+ within the project "The Application of Nanotechnology in Advanced Materials" - NanoMat (POIG.01.01.02-02002/08) co-financed by the European Regional Development Fund (Operational Programme Innovative Economy, 1.1.2).

\section{References}

[1] Sharafutdinov, C.F. Elkjaer, H.W. Pereira de Carvalho, D. Gardini, G.L. Chiarello , C.D. Damsgaard, J.B. Wagner, J.D. Grunwaldt, S. Dahl, I. Chorkendorff, J. Catal. 2014, 320, 77 -88 .

[2] F. Studt, I. Sharafutdinov, F. Abild-Pedersen, C.F. Elkjaer, J.S. Hummelshøj, S. Dhal, I. Chorkendorff, J.K. Nørskov, Nat.Chem. 2014, 6, 320 - 324.

[3] V. B. Bermudez, R. Kaplan, Phys. Rev. B. 1993, 48, 2436 - 2444.

[4] M. Grodzicki, P. Mazur, S. Zuber, J. Pers, J. Brona, A. Ciszewski, App. Sur. Sci. 2014, $304,24-28$.

[5] Horcas, R. Fernández, J.M. Gómez-Rodríguez, J. Colchero, J. Gómez-Herrero, A.M. Baro, Rev. Sci. Instrum. 2007, 78, 013705-1 - 8.

[6] More information at http://gwyddion.net/ 